\title{
Spasticity Treatment Strategies in Multiple Sclerosis
}

ISSN: 2637-7748

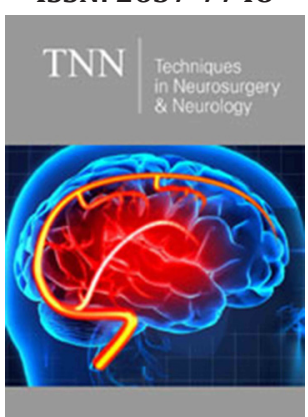

*Corresponding author: Behzad Saberi, Medical Research, Esfahan, Iran

Submission: 非 August 27, 2019

Published: 僵October 30, 2019

Volume 3 - Issue 1

How to cite this article: Behzad Saberi. Spasticity Treatment Strategies in Multiple Sclerosis. Tech Neurosurg Neurol.3(1). TNN.000551.2019.

DOI: 10.31031/TNN.2019.03.000551

Copyright@ Behzad Saberi, This article is distributed under the terms of the Creative Commons Attribution 4.0 International License, which permits unrestricted use and redistribution provided that the original author and source are credited.

\author{
Behzad Saberi* \\ Medical Research, Esfahan, Iran
}

\section{Mini Review}

Yoga, aquatherapy and stretching can be used to manage mild levels of spasticity in the patients with multiple sclerosis. In more severe cases which spasms interfere with normal functions and sleep, drug therapy would be indicated. As monotherapy, Baclofen can be the first choice which stimulates the GABA receptors. Administration of Baclofen with the initial dosage of 5 to $10 \mathrm{mg}$ three times a day and in case of necessity, increasing the administered dosage to achieve a therapeutic response or reaching the maximum tolerated dosage which can be more than $100 \mathrm{mg}$ in some patients, can be a good therapeutic strategy. Nocturnal spasms can be controlled by bedtime administration of the drug. Sedation, muscle weakness and confusion can be the side effects of the Baclofen which can make its clinical usage, limited.

Bladder function may be improved or worsened unpredictably during treatment with Baclofen. When the daily dosage of administration of Baclofen is more than $30 \mathrm{mg}$, abrupt discontinuation of the drug is prohibited because of the risk for occurring withdrawal syndrome which its clinical picture includes seizures, confusion etc.

Tizanidine as an a-adrenergic agonist can be another treatment option. It is best to be initiated very slowly which is started with $2 \mathrm{mg}$ at bedtime and gradually increased and adjusted to a maximum dosage of $12 \mathrm{mg}$ three times a day. Dry mouth, orthostatic hypotension and sleepiness are the main side effects of treatment with Tizanidine. Occurrence of motor weakness with Tizanidine treatment is lower than treatment with Baclofen. Combination therapy with low doses of Tizanidine and Baclofen can be effective with successful therapeutic results.

Benzodiazepines and Gabapentin can be another treatment options due to their musclerelaxant effects. Continuous intrathecal Baclofen administration can be used in cases with severe spasticity. Injection of Botulinum toxin can also be used for spasticity treatment in occasional cases, although its effectiveness for larger muscle groups is not so much. Also, for such cases, there are some technical difficulties which make treatment with Botulinum toxin injections, limited.

Dantrolene sodium, Clonidine and Cyproheptadine-among others-can also be used to treat spasticity in the patients with multiple sclerosis [1-11].

\section{References}

1. Young R (1994) Spasticity: a review. Neurology 44(11 Suppl 9): S12-S20.

2. Feldman R, Kelly-Hayes M, Conomy J, Foley J (1978) Baclofen for spasticity in multiple sclerosis. Double-blind crossover and three-year study. Neurology 28(11): 1094-1098.

3. From A, Heltberg A (1975) A double-blind trial with baclofen (Lioresal) and diazepam in spasticity due to multiple sclerosis. Acta Neurol Scand 51(2): 158-166.

4. Cendrowski W, Sobczyk W (1977) Clonazepam, baclofen and placebo in the treatment of spasticity. Eur Neurol 16(1-6): 257-262.

5. Penn RD, Savoy SM, Corocs D, Latash M, Gottlieb G, et al. (1989) Intrathecal baclofen for severe spinal spasticity. N Engl J Med 320(23): 1517-1521. 
6. Azouvi P, Mane M, Thiebaut J, Denys P, Remy-Neris O, et al. (1996) Intrathecal baclofen administration for control of severe spinal spasticity: functional improvement and long-term follow-up. Arch Phys Med Rehabil 77(1): 35-39.

7. Brar S, Smith M, Nelson L, Franklin GM, Cobble ND (1991) Evaluation of treatment protocols on minimal to moderate spasticity in multiple sclerosis. Arch Phys Med Rehabil 72(3): 186-189.

8. Lapierre Y, Bouchard S, Tansey C, Gendron D, Barkas WJ, et al. (1987) Treatment of spasticity with tizanidine in multiple sclerosis. Can J Neurol Sci; 14(3 Suppl): 513-517.
9. Kerty E, Stein R (1997) Treatment of spasticity with botulinum toxin. Tidsskr Nor Laegeforen 117(14): 2022-2024.

10. Shakespeare D, Young C, Boggild M (2003) Anti-spasticity agents for multiple sclerosis. Cochrane Database Syst Rev 4.

11. Dunevsky A, Perel A (1998) Gabapentin for relief of spasticity associated with multiple sclerosis. Am J Phys Med Rehabil 77(5): 451-454. 